Uniwersytet Przyrodniczo-

Humanistyczny w Siedlcach

Siedlce University of Natural

Sciences and Humanities

https://bazawiedzy.uph.edu.pl

\begin{tabular}{|l|l|}
\hline Publikacja / Publication & $\begin{array}{l}\text { The structure of the synaptonemal complexes in Meiocytes of European domestic } \\
\text { goose (Anser anser), } \\
\text { Andraszek Katarzyna, Smalec Elżbieta Maria, Czyżewska Dominika }\end{array}$ \\
\hline $\begin{array}{l}\text { DOI wersji wydawcy / Published } \\
\text { version DOI }\end{array}$ & http://dx.doi.org/10.3409/fb.56_3-4.139-147 \\
\hline $\begin{array}{l}\text { Adres publikacji w Repozytorium } \\
\text { URL / Publication address in } \\
\text { Repository }\end{array}$ & https://bazawiedzy.uph.edu.pl/info/article/UPH97635d547f544e6aad708ad6570f36e5/ \\
\hline $\begin{array}{l}\text { Data opublikowania w Repozytorium / } \\
\text { Deposited in Repository on }\end{array}$ & 22 paź 2021 \\
\hline Rodzaj licencji / Type of licence & Other open licence _ _ \\
\hline $\begin{array}{l}\text { Cytuj tę wersję / Cite this version } \\
\text { of the synaptonemal complexes in Meiocytes of European domestic goose (Anser } \\
\text { anser), Folia Biologica-Krakow, vol. 56, no. 3, 2008, pp. 139-147, DOI:10.3409/fb. } \\
56 \_3-4.139-147\end{array}$ \\
\hline
\end{tabular}




\title{
The Structure of the Synaptonemal Complexes in Meiocytes of European Domestic Goose (Anser anser)
}

\author{
Katarzyna ANDRASZEK, Elżbieta SMALEC and Dominika CZYŻEWSKA
}

Accepted April 22, 2008

\begin{abstract}
ANDRASZEK K., SMALEC E., CZYŻEWSKA D. 2008. The structure of the synaptonemal complexes in meiocytes of European domestic goose (Anser anser). Folia biol. (Kraków) 56: 139-147.

The synaptonemal complex (SC) is a protein structure which binds two homologues during prophase of the first meiotic division and assures the correct course of genetic recombination. The demonstration and identification of SCs in European domestic goose Anser anser was the aim of the current research. Standard techniques of SC identification do not allow for an analysis of their molecular structure. In meiotic cells of one-day-old nestlings and 17-week-old geese the haploid number of bivalents, darkly stained kinetochores and subtelomeric regions may be evidence for the presence of SCs. Experimental chromosome staining with the DAPI fluorochrome permitted the observation of the characteristic ladder-like structure of SCs and the course of synapsis formation within homologues from early leptotene to their degradation in late pachytene. The detailed molecular structure of synaptonemal complexes can be analysed with an electron or scanning microscope only. Because the bivalent is a direct result of the complex's presence, in the literature the presence of bivalents is equivalent to the term "synaptonemal complex". However, the bivalent and the $\mathrm{SC}$ are two different structures.
\end{abstract}

Key words: Anser anser goose, meiosis, synaptonemal complex, genetic recombination.

Katarzyna ANDRASZEK, Elżbieta SMALEC, Dominika CZYŻEWSKA, Institute of Bioengineering and Animal Breeding, University of Podlasie, Prusa 14, 08-110 Siedlce, Poland.

E-mail:andrasz@ap.siedlce.pl

Apart from variation through mutation, genetic recombination is the cause of much of the diversity of different organisms. The synaptonemal complex (SC) plays an important part in this event. It binds two homologous chromosomes and enables them to conjugate (TURNER et al. 2004). Over 50 years ago, the SC was first described in crayfish spermatocytes (MOSES 1956) and in the spermatocytes of pigeon, cat and man (FAWCETT 1956). This meiotic structure is evolutionarily conserved in the vast majority of sexually reproducing eukaryotes from mononuclear Protozoa, Fungi, and algae to vertebrates (PENKINA et al. 2001).

A completely formed SC mediates the association of prophase homologues throughout their entire length and binds them into a bivalent. The SC is a tripartite protein structure consisting of two lateral elements (LEs) and a central element (CE) situated between them. There are recombination nodules between the lateral elements of the SCs. Lateral elements border on protein cores of sister chromatids. The ends of LEs are visible in the form of globular structures called telochores. They attach the SC to the internal side of the nuclear enve- lope. In the medial position of a complex there is a ladder-like structure which is the result of a connection between LE and CE. This ladder-like structure is composed of transverse filaments (TFs). The size of the SC is species-specific and usually ranges from 70 to $240 \mathrm{~nm}$, but is also dependent on the genome size. The length of the SC corresponds to the length of prophase bivalents (MAREC 1996; PENKINA et al. 2001).

A number of investigations have shown that SCs first appear in specific places between homologues which are called pairing centres. These pairing centres are responsible for correct recognition of homologous sites and they are potential sites of genetic recombinations (MOENS 1994; ZICKLER 2006). The SC is attached to prophase chromatin loops only in a few sites. Most prophase DNA is not joined to the SC and only less than $0.5 \%$ is closely connected to this structure (RATTNER et al. 1981; MAREC 1996). The number and location of recombination nodules also correspond to the number of SC initiation sites and crossing-over loci (CARPENTER 1988; ZICKLER \& KLECKNER 1999; ANDERSON \& STACK 2005; 
ZICKLER 2006). SC formation in telomeric regions starts when the bouquet stage appears, however, the origin of this convergence and factors influencing this dependence are still unknown (ZICKLER 2006). Nucleolar organizer regions (NORs) of chromosomes are the last to achieve completely formed synapsis (RASMUSSEN 1986). The considerable delay of synapsis formation, associated with incomplete pairing, is a typical phenomenon between the ZW pair observed in moths (WANG et al. 1993) or birds (SOLARI 1977). The SC retains its structure until late diplotene. The CEs are first to disintegrate. Then LEs dissociate along their long axes during a multistage decondensation process (PENKINA et al. 2001).

Because it includes the most important enzymatic complexes responsible for the occurrence of crossing-over, the SC plays the key part in the meiotic recombination process (BÖRNER et al. 2004; DE VRIES et al. 2005; ZICKLER 2006). Moreover, the SC binds non-homologous chromosomes and also enables the recombination of homologous fragments only (ZICKLER 2006). It has been postulated that early-prophase elements of SC are responsible for the detection and the resolving of interchromosomal tangles - interlockings (RASMUSSEN 1986).

Sex chromosome pairing and autosome pairing in the cells of homogametic organisms share the same course. Substantial morphological and genetic differentiation between XY and ZW pairs is observed in organisms whose sex is determined by the aforementioned pairs. The length as well as genetic composition of these chromosomes pose a problem. The behaviour of these chromosomes during conjugation seems to be coerced and somewhat unnatural in most cases. Despite the difficulties described, the process of pairing in these chromosomes is correct, which proves that SCs have substantial adaptive abilities and dynamics (MAREC 1996; PAGE et al. 2006). Heterochromosomes show homology only in a few areas in birds and mammals, in contrast to fish, in which the differences between sex chromosomes are considerably smaller (PAGE et al. 2006).

All of the karyologically studied birds (about $10 \%$ of the living species) have a heterogametic system of sex determination in females in the form of a ZW pair. Avian sex chromosomes are rich in euchromatin, with the exception of centromeric regions and the short arm of the $\mathrm{W}$ chromosome. The W chromosome is often metacentric and entirely consists of heterochromatin (PIGOZZI \& SOLARI 1999b). During pachytene the axes of ZW chromosomes form a bivalent bound by a SC. The length of the SC corresponds to the length of the W axis. Next, from late to mid-pachytene, the unpaired section of the $\mathrm{Z}$ arm shortens into a streamer-like structure, which achieves the length of lateral elements of a completely formed SC. In this way, the $\mathrm{Z}$ arm forms a loop around the straight $\mathrm{W}$ arm. The size of this loop corresponds to the size of the nonhomologous pairing region in this bivalent (SOLARI 1977).

The aim of the current research was to demonstrate and identify SCs in the European domestic goose (Anser anser).

\section{Material and Methods}

Females and males of the European domestic goose (Anser anser) were selected for investigations. One-day-old goslings from post-hatching faulty groups, and 17-year-old ganders from industrial slaughter were chosen. Ovaries and testicles sampled post mortem in the hatchery and during slaughter constituted the research material.

Preparations were prepared by the modified technique of COUNCE and MEYER (1973), making it possible to use this method for identification of vertebrate SCs (ŚWITOŃSKI 1991; LECHNIAK et al. 1997; SŁOTA 1998). In order to observe SCs, the preparations were experimentally prepared using the meiotic chromosome isolation technique prepared for Gallus gallus cocks (POLLOCK \& FECHHEIMER 1978).

Preparations were stained with silver nitrate $\mathrm{AgNO}_{3}$ (HOWELL and BLACK 1980). Moreover, as an experiment, the DAPI fluorochrome 4',6Diamidino-2-phenyindole staining (SCHWEIZER et al. 1978) of preparations prepared by the technique of POLLOCK and FECHHEIMER (1978) was applied.

The preparations obtained were analysed with an Olympus BX 50 light microscope, magnified 100 times (the microscope was equipped with a fluorescence attachment), and filed by means of an analogous Panasonic video camera. A detailed computer analysis was conducted by the Multiscan system of image analysis and graphic programs compatible with the system. The preparations were analysed paying special attention to the presence of bivalents, the presence being the result of the existence of SCs.

\section{Results}

Analysis of preparations obtained by means of the COUNCE and MEYER technique (1973)

No cells with formed SCs were found in the chromosomes of the preparations obtained from 
one-day-old goslings. Only occasionally were there cells observed in which SCs occurred only within macrobivalents, whereas microchromosomes were still in the form of a decondensed chromatin strand. Most of the cells had nuclei without visible chromosomes and with more or less condensed chromatin. The presence of SCs was indicated by few bivalents - structures resulting from the activity of SCs.

Figure 1 presents prophase of the first meiotic division. In Figure 1a cells with decondensed chromatin are visible, typical of pre-leptotene, in which chromatin fills up the whole cellular nucleus. It is not possible to distinguish individual chromosomes. Cells of this kind constituted the majority of all the analysed cells of one-day-old goslings. Figure $1 \mathrm{~b}$ shows a cell with the first macobivalent developed (arrow). The dark structure in the subproximal part of bivalents and the dark structures against a background of chromatin are kinetochores, which are intensely red (open arrow) after application of silver nitrate staining. In Figure $1 \mathrm{c}$ the first two well-developed macrobivalents are also visible. Kinetochores are the darkly stained structures in the subproximal macrobiva- lent regions (arrows). Their presence at this stage proves that the first two goose bivalents are submetacentric. In Figure 1d kinetochores (arrow) are also visible on the first macrobivalents, as well as darkly stained regions of telomeres (open arrows). Figure 1e presents a cell with developed SCs within the first four macrobivalents and the ZW univalent, as well as within the acrocentric bivalents arranged according to size. The subtelomeric location of kinetochores of acrocentric bivalents 6 and 7 is indicated by arrows.

Preparations obtained from 17-week-old ganders were characterised by cells which had a complete set of bivalents. This was indicated by the number of kinetochores (40) which equals the haploid number of Anser anser. The conclusions as to the presence of SCs were drawn on the basis of the presence of bivalents. Bivalents in cells were densely packed and very thin. Such bivalent structure made it possible only to identify kinetochores and darkly stained subtelomeric regions. Moreover, developed spermatids were identified (Fig. 2e).

Figure 2a presents a cell at a very early stage of zygotene. At this stage, some macrobivalents (open arrow) as well as microbivalents (arrow) can

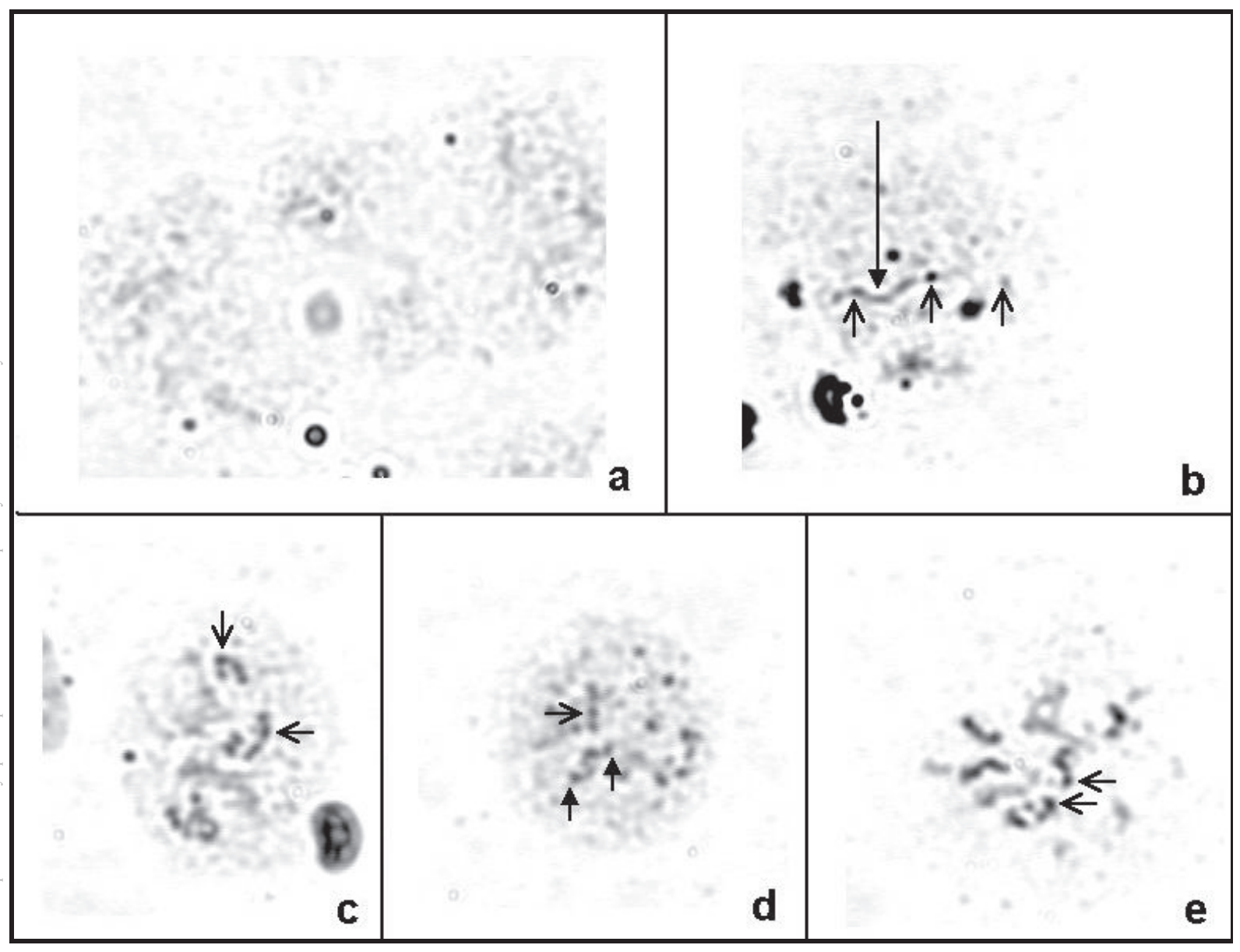

Fig. 1. Chromatin organisation in one-day-old gosling cells; isolation - COUNCE and MEYER (1973), staining - HOWELL and BLACK (1980); a - preleptotene, b, c and d-early zygotene, e - late zygotene. 
be identified. What is more, the kinetochore localisation and typical dark telomeric parts can be determined. These structures cannot be identified on all bivalents. In photograph $2 \mathrm{~b}$ all bivalents are already visible, which is indicated by the number of kinetochores. Kinetochores are identified on macrobivalents in subproximal bivalent regions (arrow) and darkly stained subtelomeric regions (open arrows). In turn, on acrocentric microbivalents (Fig. 2c) two darkly stained structures can be identified: a smaller one in one of the subtelomeric regions (arrow) and a larger one in the proximity of the second telomere. Most likely the larger structure is a telomeric and kinetochoric (open arrow) region, observed as one signal in acrocentric bivalents. Figure $2 \mathrm{~d}$ shows pachytene of the first prophase of meiotic division and all the completely developed bivalents. The macrobivalents are long and easily identified. Within them it is possible to distinguish kinetochores as well as telomeric regions. What is more, varied bivalent lengths can be observed, from the longest first bivalent (open arrow) to very short acrocentric microbivalents (arrow) within which both kinetochores and telomeres can be easily distinguished.
Analysis of preparations following the POLLOCK and FECHHEI technique (1978)

Preparations made according to the POLLOCK and FECHHEIMER technique (1978) were characterised by well visible bivalents. On those prepared using the HOWELL and BLACK technique (1980), it was possible to identify macro- and microbivalents. However, it was not possible to organise them according to size and refer them to the karyotype of mitotic chromosomes. It was possible to indicate individual macro- and microbivalents and to estimate their number, which oscillated around 40. A large number of bivalents and lack of dispersion typical of species characterised by a large diploid number prevented a precise determination of the bivalent number. Moreover, as a result of hypotonic shock, the structure of chromosomes became looser and kinetochores as well as dark subtelomeric regions observed on the chromosomes stained with the COUNCE and MEYER technique (1973) became less clear. They were not observed on all bivalents, nor in all the analysed cells. However, in a few cells it was possible to observe individual bivalent

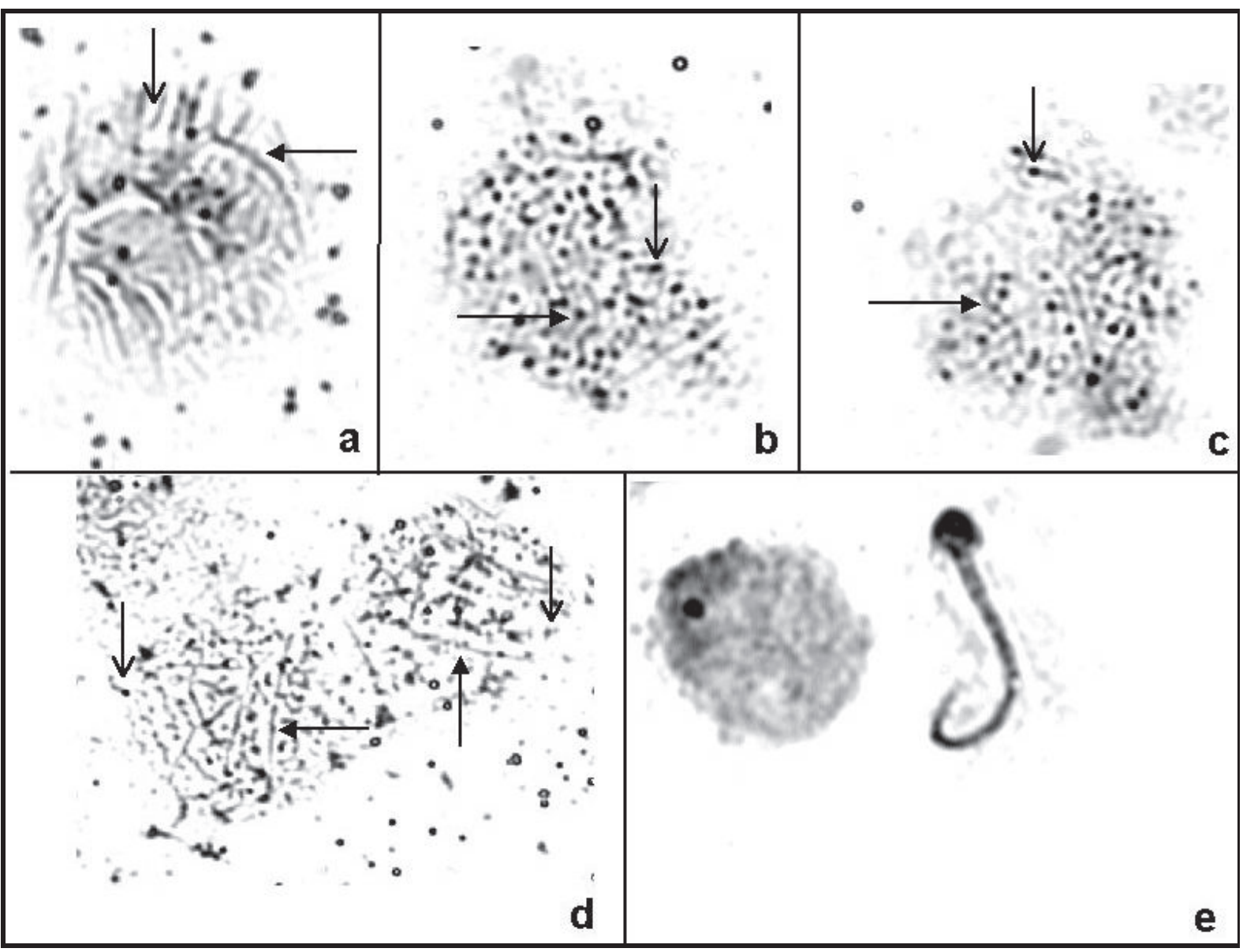

Fig. 2. Bivalent structure in 17-day-old gander cells; isolation - COUNCE and MEYER (1973), staining - POLLOCK and FEHCHEIMER (1978); a - early zygotene, b and c - late zygotene, d - pachytene, e - spermatids. 


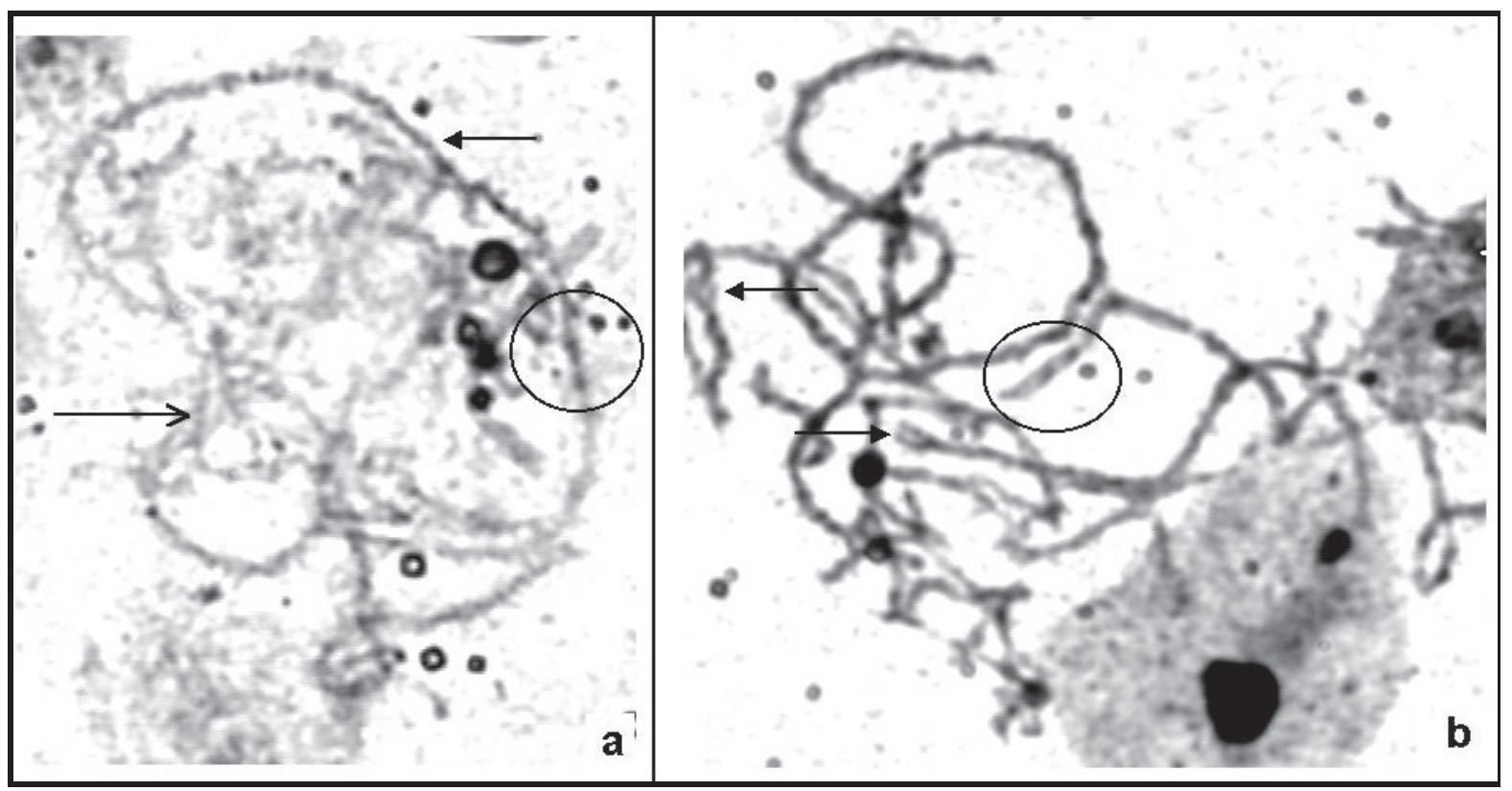

Fig. 3. Bivalent structure in 17-day-old gander cells; isolation - COUNCE and MEYER (1973), staining - HOwELL and BLACK (1980); a - early pachytene, b - late pachytene/ early diplotene.

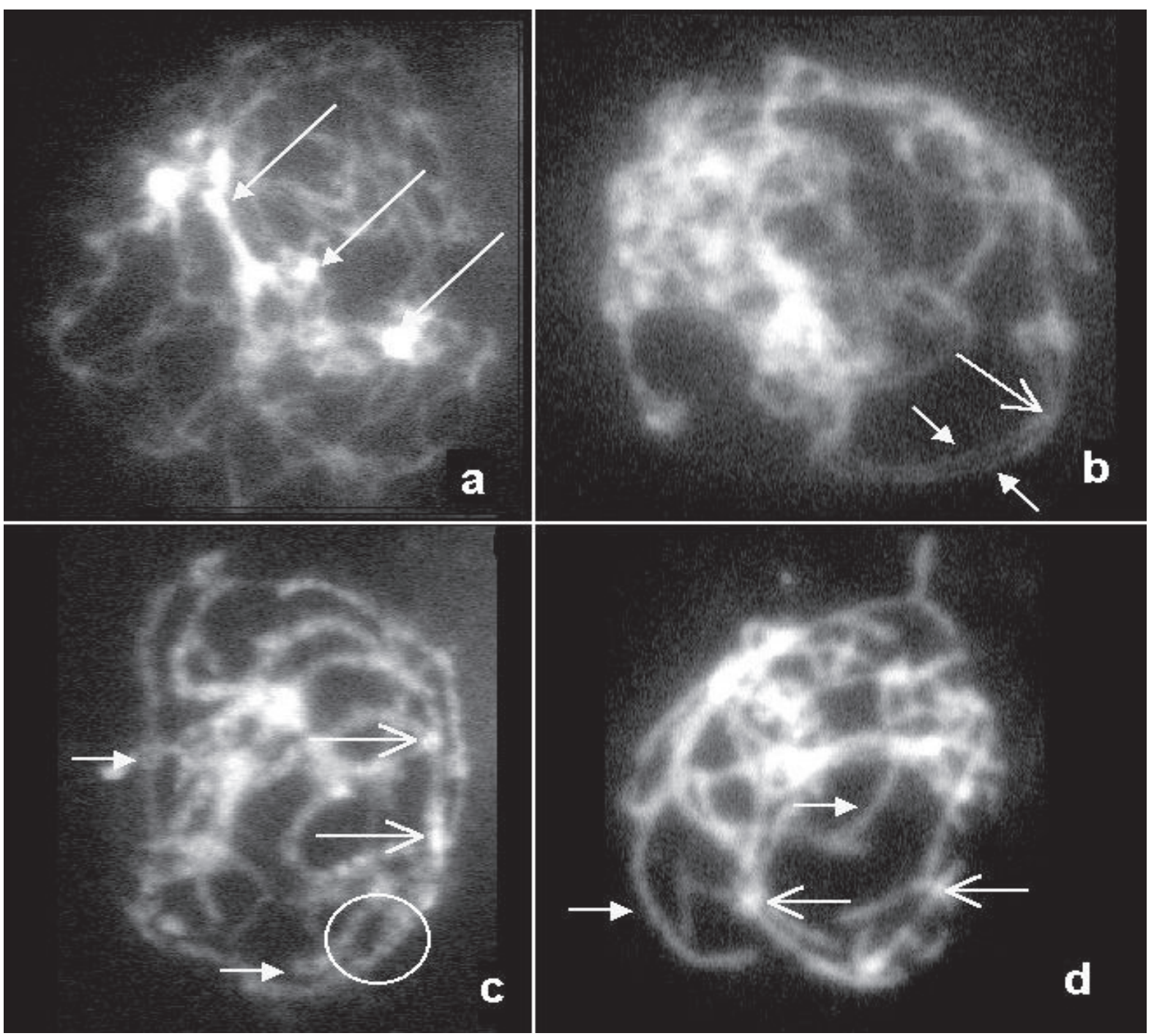

Fig. 4. Bivalent structure in 17-day-old gander cells; isolation - COUNCE and MEYER (1973), staining - SCHWEIZER et al. (1978); a - early leptotene; b - early zygotene; c - late zygotene, $\mathrm{d}$ - pachytene. 
homologues, which indicates that SC degradation had taken place.

Figure 3a shows a cell with developed SCs within bivalents. The complex structure is well visible on both macrobivalents (open arrow) and microbivalents (arrow). By contrast, kinetochores and telomeric regions are poorly visible but can be seen in the form of dark blocks against a background of the ladder-like bivalent structure (circle). The ladder-like structure visible alongside the bivalent is typical of pachytene when the SC is fully formed. Figure $3 \mathrm{~b}$ presents a cell in which the beginning of SC degradation is visible, and it is possible to distinguish individual bivalent homologues (arrows). The typical SC structure can still be detected in the form of alternating dark and light chromatin regions (circle) similar to the highresolution banded pattern on mitotic chromosomes. Such cells are typical of late pachytene and the beginning of diplotene.

The experimental DAPI-stained preparations were found to be the best for SC identification. On the preparations, cells at the leptotene stage were found with well visible individual and thin chromosomes. Moreover, not fully conjugated bivalents typical of zygotene were detected, within which individual homologues could be distinguished. DAPI staining revealed the characteristic ladder-like SC structure as well as fully developed bivalents.

Figure $4 \mathrm{a}$ presents chromosomes as individual homologues. The chromosomes are thin, long and not fully isolated from condensating chromatin (light areas marked with arrows). A large number of chromosomes and their looping prevent not only identification of individual chromosomes but also determination of their telomeres and centromeres. Figure $4 \mathrm{~b}$ shows a cell during zygotene. Bivalent homologous chromosomes are already partly bound by synapsis (arrow). Open arrows mark bivalent homologues before complete stabilisation of SCs. Homologous chromosomes are visible in those places. Sites of incomplete synapsis occur in interstitial chromosome parts, which results from SC functioning and structure. In Figure $4 \mathrm{c}$, along their whole length, bivalents have a ladder-like structure typical of synapsis, as well as well-visible, brightly fluorescing telomeres and kinetochores (arrow). An arrangement of two homologues joined by a synapsis (circle), the beginning of SC degradation (open arrow) and two bivalent homologues after degradation of synapsis are also clearly visible. Figure $4 \mathrm{c}$ shows cells with completely formed bivalents. Chromosomal chromatin is condensed enough to distinguish individual bivalents (open arrows). Brightly fluorescing kinetochores are also apparent (arrows).

\section{Discussion}

An analysis of preparations obtained from oneday-old goslings has shown that macrobivalents are the first to achieve complete synapsis. The SC in higher organisms begins to form from telomeric regions (PENKINA et al. 2002), so shorter microchromosomes might be expected to be the first to achieve synapsis. The phenomenon provides an explanation to the specific character of the bird genome which, unlike that of mammals, possesses a marked number of telomeric sequences in the interstitial parts of chromosome arms (SOLOVEI et al. 1994; NANDA et al. 2002). The occurrence of interstitially located telomeric sequences on macrochromosomes is connected with an increase in the number of sites where formation of SCs is initiated, which explains why synapsis is achieved more rapidly. SANTOS et al. (1993) observed that in submetacentric bivalents SC formation begins from subtelomeric regions of chromosomes. Two potential sites of initiation exist in acrocentric bivalents, i.e. in the distal and proximal parts of the $q$ arm. The short $\mathrm{p}$ arms pair much later.

In geese the largest macrochromosomes are submetacentric, whereas microchromosomes are acrocentric, so the theory of SANTOS et al. (1993) and the presence of interstitial telomeric sequences in chromosomes may provide an explanation to why macrochromosomes and not microchromosomes undergo synapsis first. Moreover, compared with macrochromosomes, microchromosomes are characterised by a lower adeninethymine content, accompanied by a higher guanine-cytosine content (FILLON et al. 1998; GREGORY 2002). Sequences rich in G-C constitute about $60 \%$ Zyg DNA which is responsible for linking with SC. Zyg DNA undergoes replication not during the pre-meiotic phase $\mathrm{S}$, but as late as in zygotene (MAREC 1996) so synapsis formation is delayed at those sites. In turn, replication delaying may follow from joining Zyg DNA and the components of the complex which is formed during zygotene, or difficulties in breaking triple bonds between G-C bases. Thus the macrochromosomes poorer in G-C content enter prophase of meiotic division I fully replicated and, as a result, can achieve synapsis first.

It remains unexplained whether the phenomenon of synapsis not being achieved simultaneously is intended or coincidental, being a consequence of the occurrence of interstitial telomeric sequences or Zyg DNA sequences, when one bears in mind that most genes are concentrated in delayed microchromosomes (FILLON et al. 1998; GREGORY 2002). Perhaps it is associated with the loop repair mechanism of chromosomes interlooking. Delayed synapsis allows for the repair mechanism to 
check if the bivalent structure is correct, which somehow prevents loss of valuable chromosome fragments. Unfortunately, this hypothesis cannot be verified because, apart from birds, no animal group has micro- and macrochromosomes in such form.

Also, the characteristic morphology of the ZW pair, which assumes the univalent form in which chromosome $\mathrm{W}$ is joined to the distal part of chromosome $\mathrm{Z}$, is a consequence of SC formation starting from subtelomeric sequences. Moreover, due to the joining of all of the chromosomes to form a bivalent from telomeric sequences, the risk of losing their distal endings is reduced to a minimum. Such a situation would not be possible if the complex formation proceeded from the centromere towards the chromosomal endings. One can think that the role of SCs is to stabilise the bivalent structure, just like the role of telomers is to stabilise the chromosome structure.

The structure and functioning of the SC are species-specific (PENKINA et al. 2002). Developed bivalents on preparations obtained from one-day-old Anser anser goslings were observed only within the first chromosomal pairs of a small percentage of analysed cells. In similar research conducted on one-day-old Leghorn chickens, PIGOZZI (2001) obtained preparations with perfectly developed SCs. In Pterocnemia pennata and Rynchotus rufescens also pachytene oocytes were observed 3-5 days before hatching, whereas in $\mathrm{Co}$ lumbia livia SCs appeared as late as on the seventh day after hatching (PIGOZZI \& SOLARI 1999a,b). Pachytene oocytes can be analysed in the third day of life in Drosophila melanogaster (CHUBYKIN 2001). In the Syrian hamster Mesocricetus auratus SCs were observed on the seventh day of life, whereas in mice on the first day of life. The pachytene stadium of prophase I occurs in Canis familiaris between the $10^{\text {th }}$ and $30^{\text {th }}$ day of age, however, up to $10 \%$ of examined one-day-old puppy population the presence of pachytene oocytes was detected (LECHNIAK et al. 1997). In the case of birds it is the oocyte meiotic division I that is most valuable because, due to different sex determination of abraxas type, conjugation of pair ZW and untypical heterochromosome morphology can be observed only in females.

Compared with chickens, geese mature at an older age. What is more, goose as a typical waterfowl species are evolutionary closer to reptiles then chickens. The physiological and evolutionary differences of both species may explain the lack of the pachytene stage in one-day-old geese and its presence in chicks of the same age which, in addition, have prominent SCs. What is also interesting is the presence of mature spermatids in testicles of 17-day-old geese. In Gallus domesticus males, order I spermatocytes appear in the $6^{\text {th }}-8^{\text {th }}$ week of age, order II spermatocytes in the $10^{\text {th }}-12^{\text {th }}$ week of age, and spermatids in the $14^{\text {th }}-16^{\text {th }}$ week of age (RZALSA 2005). The presence of spermatids in 17week-old geese may indicate that the birds compensate for the low meiosis rate at the initial stage of spermatogenesis. Although ganders reach full reproductive maturity later than cocks, the spermatids in both species appear at the same time.

An application of conventional techniques of SC identification and staining of preparations does not allow for the identification and analysis of SC molecular structure. SCs in preparations obtained from one-day-old goslings can be inferred on the basis of the presence of macrobivalents as well as darkly stained kinetochores and subtelomeric regions. On preparations obtained from 17-weekold ganders, SCs were once again deduced from the presence of the complete set of bivalents as well as the number of kinetochores typical of the haploid set of chromosomes. Moreover, the bivalents were very thin and poorly dispersed, which additionally made them more difficult to analyse. Kinetochore proteins show affinity to heavy metals, and silver staining makes them prominent especially on thin bivalents obtained by means of the technique of COUNCE and MEYER (1973). However, darkly stained kinetochores and the haploid number of bivalents were the only evidence for the presence of synaptonemal complexes in goose cells.

SCs revealed after the application of analogous isolation and chromosome staining techniques was observed in man (SOLARI 1980), Locusta migratoria (COUNCE \& MEYER 1973; MACGREGOR \& VARLEY 1988), cattle (ŚWITOŃSKI \& STRANZINGER 1998), Rattus norvegicus (PUJOL et al. 1988), Anas platyrhynchos (SOLARI \& PIGOZZI 1993), Canis familiaris (LECHNIAK et al. 1997), Gallus domesticus (SOLARI 1977) and Sus scrofa (SŁOTA 1998).

However, detailed analysis of the aforementioned works and the comparison of the results suggest that in the available literature the presence of bivalents is tantamount to the term "synaptonemal complex" as the bivalent is a direct result of the existence of the $\mathrm{SC}$ without which it cannot be formed.

In the discussed studies, the best results were obtained when the meiotic chromosome isolation technique described by POLLOCK and FEHCHEIMER (1978) was applied and followed by silver nitrate staining as well as experimental staining with the DAPI flourochrome. After application of the aforementioned techniques, homologous chromosomes and bivalents were prominent. What is more, the typical ladder-like structure of SCs resulting from a di- 
verse protein composition of lateral elements was observed. In addition, the DAPI-stained preparations had unique structures observed during basic cytogenetic analysis, i.e. two parallel homologous chromosomes just before synapsis.

An application of the alternative POLLOCK and FEHCHEIMER technique (1978) required the use of $0.8 \%$ sodium citrate solution. The ready preparations were conventionally stained with silver nitrate and experimentally with the DAPI fluorochrome. Such a protocol has not been described in the available literature so far, thus the results can only be indirectly compared to research carried out by other workers and in other animal species. The application of stronger hypotony enabled obtaining longer chromosomes characterised by looser chromatin structure than conventionally isolated chromosomes. Furthermore, on a macro scale a SC with a developed ladder-like structure was observed along the whole length of the chromosome. The structure results from nonuniform protein composition of SC lateral elements, and resembles a high-resolution banding pattern typical of meiotic chromosomes. An experimentally applied method of staining with the DAPI fluorochrome made it possible to obtain unique preparations on which individual homologous chromosomes were observed before forming the bivalent structure. Also, as a result of fluorochrome application, the typical ladder-like structure formed by elements of lateral synaptonemal complexes was prominent.

According to MACGREGOR and VARLEY (1988) paired or unpaired chromosome regions may be indicators of the location of such marker structures as: centromeres, nucleolar organizer regions, nuclei, telomeres and even heterochromatin regions. Such preparations may be very useful for analysing prophase chromosomes, and can be used to prepare the so-called SC karyotypes. The karyotypes would make it possible to observe pairing initiations, sequences participating in pairing, the frequency of recombination occurrence, as well as potential meiotic chromosome structure anomalies. In the opinion of MAREC (1996), Zyg DNA, whose single copies of short (5-10 kb) sequences are located along the length of chromosomes, is responsible for the specificity of the DNA-SC bond. Afterwards the complex lateral elements join to DNA in strictly determined sequences, and thus through inference the ladder-like SC structure can be treated as a bivalent banded pattern indicating, similarly to banded staining, the location of specific sequences in the chromosome.

The detailed molecular SC structure can be analysed only with electron or scanning microscopy. With the optic microscope, even with a high- resolution image under large magnification, it is only possible to grasp a bivalent structure with clearly outlined chromosomes at the synapsis stage. Detailed analysis of SC structure, the process of SC formation and specific combination of particular chromosomes with DNA can be treated as one of the poultry genome mapping elements. In the literature the presence of bivalents is equivalent to the determination of the SC because the bivalent is the direct result of the SC presence. Yet, the bivalent and the synaptonemal complex are two different structures.

\section{References}

ANDERSON L. K., STACK S. M. 2005. Recombination nodules in plants. Cytogenet. Genome Res. 109: 198-204.

BÖRner G. V., KleCKNer N., Hunter N. 2004. Crossover/noncrossover differentiation, synaptonemal complex formation, and regulatory surveillance at the leptotene/zygotene transition of meiosis. Cell 117: 29-45.

CARPENTER A. T. C. 1988. Thoughts on recombination nodules, meiotic recombination and chiasmata. (In: Genetic Recombination, R. KUCHERLAPATI, G. R. SMITH eds. American Society of Microbiology, Washington DC.): 529-548.

CHUBYKIN V. L. 2001. Structural characteristics of the chromocenter in ovary cells of c (3) G and nod mutants of Drosophila melanogaster. Genetica 111: 143-153.

Counce S. J., MEYER G. F. 1973. Differentation of the synsptonemal complex and the kinetochore in Locusta spermatocytes studied by whole mout electron microscopy. Chromosoma 44: 231-253.

DE VRIES F. A., DE BOER E., VAN DEN BOSCH M., BAARENDS W. M., OOMS M., YUAN L., LIU J. G., VAN ZEELAND A. A., Heyting C., PASTinK A. 2005. Mouse Sycp1 functions in synaptonemal complex assembly, meiotic recombination, and XY body formation. Genes Dev. 19: 1376-1389.

FAWCETT D. W. 1956. The fine structure of chromosomes in the meiotic prophase of vertebrate spermatocytes. J. Biophys. Biochem. Cytol. 2: 403-406.

Fillon V., MOrisson M., ZOOROB R., AufFraY C., DOUAIRE M., GELLIN J., VIGNAL A. 1998. Identification of sixteen chicken microchromosomes by molecular markers using two colour fluorescent in situ hybridization (FISH). Chrom. Res. 6: 307-313.

GREGORY T. R. 2002. A bird's-eye view of the C-value enigma: genome size, cell size, and metabolic rate in the class aves. Int. J. Org. Evol. 56: 121-130.

Howell W. M., BLACK D. A. 1980. Controlled silver-staining of nucleolus organizer regions with a protective colloidal developer: a 1-step method. Experientia 36: 1014-1015.

LECHNIAK D., SosnowsKi J., ŚwiTOŃSKI M. 1997. Identification of synaptonemal complexes in postnatal oocytes from one-day-old puppies of domestic dog (Canis familiaris). J. Appl. Genet. 38: 477-479.

MACGREGOR H. C., VARLEY J. 1988. Chromosome in meiosis. (In: Working with Animal Chromosomes, ed. John Wiley \& Sons): 37-72.

MAREC F. 1996. Synaptonemal complexes in insects. Pergamon 3: 205-233.

MoEns P. B. 1994. Molecular perspectives of chromosome pairing at meiosis. Bio Essays 16: 101-106.

Moses M. J. 1956. Chromosomal structures in crayfish spermatocytes. J. Biophys. Biochem. Cytol. 2: 215-218

NANDA I., SChrama D., FEICHTINGER W., HAAF T., SCHARTL M., SCHMID M. 2002. Distribution of telomeric 
(TTAGGG) $)_{\mathrm{n}}$ sequences in avian chromosomes. Chromosoma 111: 215-227.

Page J., DE la Fuente R., Gómez R., Calvente A.,. Viera A., PARra M. T., SANTOS J. L., Berríos S., FERnÁndeZ-Donoso R., SuJA J. Á., Rufas J. S. 2006. Sex chromosomes, synapsis, and cohesins: a complex affair. Chromosoma 115: 250-259.

PEnKina M. V., Karpowa O. I., Bogdanov F. Yu. 2002. Synaptonemal complex proteins: specyfic proteins of meiotic chromosomes. Mol. Biol. 3: 304-313.

PIGOZZI M. I. 2001. Distribution of Mlh1 foci of the synaptonemal complexes of chicken oocytes. Cytogenet. Cell Genet. 95: 129-133.

PigOzZI M. I., Solari A. J. 1999a. Equal freqencies of recombination nodules on both sexes of the pigeon suggest a basic difference with eutherian mammals. Genome 42: 315-321.

PIgOZZI M. I., SOLARI A. J. 1999b: The ZW pairs of two paleognath birds from two orders show transitional stages of sex chromosome differentiation. Chromosome Res. 7: 541-551.

POLLOCK D. L., FECHHEIMER N. S. 1978. The chromosomes of cockerels (Gallus domesticus) during meiosis. Cytogenet. Cell Genet. 21: 267-281.

Pujol R., Garcia M., FreiXa L., EgOzCuE J. 1988. Sequential study of the synaptonemal complex in rat (Ratus norvegicus) oocytes by light and electron microscopy. Genetica 77: 179-187.

RASMUSSEN S. W. 1986. Initiation of synapsis and interlocking of chromosomes during zygotene in Bombyx spermatocytes. Carlsberg Res. Commun. 51: 401-432.

Rattner J. B., Goldsmith M. R., Hamkalo B. A. 1981. Chromosome organization during male meiosis in Bombyx mori. Chromosoma 82: 341-351.

RZĄSA, J. 2005. Chosen questions with birds' physiology. (In: Fizjologia Zwierząt, PWRiL ed., Warszawa): 701-732. (In Polish)

SAnTos J. L., DEL CERro A. L., DíEZ M. 1993. Spreading synaptonemal complexes from the grasshopper Chorthippus jacopsi: pachytene and zygotene obserwations. Hereditas 118: $235-241$.

SCHWEIZER, D., AMBRos P., ANDRLE M. 1978. Modification of DAPI banding on human chromosomes by prestaining with a DNA-binding oligopeptide, antibiotic distamycin A. Exp. Cell Res. 111: 327-332.

SŁOTA E. 1998. Chromosome polymorphism in swine. Rocz. Nauk. Zoot., Ph.D. Thesis, IZ Kraków 7: 1-58. (In Polish).

SOLARI A. J. 1977. Ultrastructure of the synaptic autosomes and ZW biwalent in chicken oocytes. Chromosoma 64: 155-165.

SOlARI A. J.. 1980. Synaptonemal Complexes and Associated Structures in Microspread Human Spermatocytes. Chromosoma 81: 315-337.

SOLARI A. J., PIGOZZI M. I. 1993. Recombination nodules and axial equalization in the ZW pairs of the Peking duck and the Guinea fowl. Cytogenet. Cell Genet. 64: 268-272.

Solovei I. V., GAginskya E. R., MACGREGOR H. C. 1994. The arrangement and transcription of telomere DNA seqences at the ends of lampbrush chromosomes of birds. Chromosome Res. 2: 460-470.

ŚWITOŃSKI, M., 1991: Paracentric inversion involving NOR of chromosome 8 in a boar: studies of synaptonemal complexes under a light microscope. Genet. Sel. Evol. 23: 181-189.

Świtoński M., Strazinger G. 1988. Synaptonemal complexes in domestic mammals-a review. J. Hered. 89: 473-480.

Turner P. C., Mclennan A. G., Bates A. D., White M. R. H. 2004. Molecular Biology, PWN ed., Warszawa. (In Polish).

WANG Y. X., MAREC F., TRAUT W. 1993. The synaptonemal complex complement of the wax moth, Galleria mellonella. Hereditas 118: 113-119.

ZICKLER D., KLECKNER N. 1999. Meiotic chromosomes: integrating structure and function. Annu. Rev. Genet. 33: 603-754.

ZICKLER D. 2006. From early homologue recognition to synaptonemal complex formation. Chromosoma 115: 158-174. 